\title{
“I CAN DO THIS - BETTER THAN I THOUGHT" - INSTRUCTORS” EXPERIENCES OF THE DIGITAL SUMMER TERM 2020
}

Svenja Bedenlier, Claudia Schmidt, Stefanie Gerl, Sonia Hetzner, Mona Schliebs, Katja Sesselmann, Friedrich-Alexander-University Erlangen-Nürnberg, Germany

\section{Abstract}

With the Covid-19-induced situation in the summer term 2020, instructors at campus universities were confronted with the need to radically modify their face-to-face teaching practices. Switching to teaching fully online, they needed to cope with an oftentimes little chartered pedagogical territory, adapt to online distance education practices and do so in a very short time. As part of an institutional evaluation of the summer term, this study draws on the responses of $n=29$ instructors who reported zero years of prior experience with digital teaching at the outset of the summer term at one German university. It provides evidence on the kinds of tools that they used in their teaching, the most important learning experiences they identified and the elements they would like to modify in their future teaching.

Keywords: Online Learning, Emergency Remote Teaching, Instructors, Interaction, Support Structures, Higher Education

\section{Introduction}

With the global spread of the COVID-19 pandemic, the year 2020 marks a turning point in all aspects of everyday life; also including higher education (Marinoni, van't Land, \& Jensen, 2020). Campus universities across the world resorted to full online teaching and learning during the summer term, adopting emergency remote teaching as a way to cope with this global health threat (Hodges et al., 2020). Numerous ad hoc initiatives were created to support instructors in higher education to carry out their online teaching (for example, EDEN, 2020; Hochschulforum Digitalisierung, 2020), focusing on how to support students, implement different educational technologies or develop strategies for online teaching. However, Hodges et al. (2020) also stress that emergency remote teaching is different from long-term conceptualized and implemented online learning as it had been on the steady rise prior to Covid-19. Switching to teaching online can be a challenge for instructors as such (Adnan, 2018), which was exacerbated by the urgency of the situation 
in March 2020. The group of instructors, $n=29$, that is in the focus of this study reported to have zero years of experience with digital teaching, which makes them an interesting group to study when it comes to transitioning from face to face teaching to fully online settings. This investigation, part of an evaluation study of the summer term 2020 at one Germany university, revolves around their usage of digital tools, major perceived personal learnings and their intentions to modify course elements.

Briefly touching on some differentiating elements between online learning and emergency remote teaching, we delineate the study context, the approaches to data collection and analysis and then present our findings before discussing them against the background of the study limitations.

\section{Designing online learning and teaching online}

Following from the ADDIE model, Bates summarizes standardized good quality in the design of online courses to rely on "clear learning objectives, carefully structured content, controlled workloads for faculty and students, integrated media, relevant student activities, and assessment strongly tied to desired learning outcomes" (Bates, 2019; p.130). In contrast to face to face courses, online courses are closely associated with shared responsibilities that is the design oftentimes being in the hands of instructional designers and the actual delivery carried out by instructors (Rapanta et al., 2020). The demands and subsequent tasks that arise for instructors are depicted according to the progression of an online course (Salmon, n. d), indicating the complexity of teaching online. However, Baran et al. (2011) conclude in their review on the roles and competences in online instructors that "there is the tendency for online teachers to lean to their traditional teaching practices as reference points, the affordances and limitations of online environments will pose new challenges for them as they try to operate within their existing sets of beliefs and practices" (p.435), calling to professional development programs to take this into consideration as well as offering support during this potentially transformative learning experience.

\section{Designing emergency remote teaching}

In principal and in pursuit of pedagogical goals in the higher education classroom, the demand for high-quality teaching has not changed with the Covid-19 pandemic. The conditions had, however, and oftentimes did not allow for an extended design and course implementation phase (Hodges et al., 2020). Furthermore, instructors needed to both develop and deliver the courses - oftentimes also requiring to make themselves familiar with tools that they had not used previously (Brooks \& Grajek, 2020; Rapanta et al., 2020). Developing and finding their "teacher-self" (Baran et al., 2011; p.435) in the online classroom might have been even more challenging that it would have been under regular circumstances. With numerous pieces of advice being offered to instructors (e.g. Bates, 
2020) and ad hoc publications being made available to instructors (e.g. O'Keefe et al., 2020), instructors in Barton's (2020) perceived field-specific intended learning outcomes at risk as well as resorting to teaching modalities less student-centred.

\section{Research Questions}

The study addresses the following questions, aiming at providing insights that can work into further service provision at the respective university and other institutions alike.

- Which digital elements did instructors employ in their teaching?

- What do instructors report as their most important learning experience?

- What elements of their online teaching do they want to modify?

\section{Institutional Context}

The institution serving as the case example of this study is a large, comprehensive German university. The institution's e-learning support and consultation unit is centrally organized, complemented by an e-learning coordinator in each of the five faculties. For the past eight years, the e-learning unit has grown in staff numbers due to a national large scale funding project targeted at improving teaching quality (Bundesministerium für Bildung und Forschung, 2020); this also enabled extended support and consultation services to the instructors. Against the backdrop of the immediate need to collectively implement online learning formats across the university in the spring of 2020, an additional ad hoc support program was established. This included the possibility for instructors to obtain small-scale funding for equipment and student assistants, receive support in the design and implementation of their digital course format and other services related to quick-starting online teaching.

\section{Method}

In the second half of the summer term 2020, a survey with both open and closed questions was sent out to 371 instructors at the university who had previously either received support in the context of the long-term teaching development project and/or in the ad hoc support program from March 2020 on. The survey was distributed via the university learning management system; clearance on data protection was obtained from the institutional data protection officer. The survey was primarily motivated to receive concerted feedback from the instructors on the services offered through the e-learning support unit as well as understanding their prospective needs in further digital or hybrid semesters. After evaluation of the responses obtained, $\mathrm{n}=88$ cases were considered for descriptive analysis; out of those 79 answered all questions, and nine the major part of the survey. For the present study, we focus on the answers of $n=29$ instructors who reported to have zero years of experience with digital teaching. We can therefore assume that the experiences 
reported by this group primarily stem from the digital summer term 2020-unless they gained experience with digital teaching in the winter term 2019/20 or acquired knowledge on the topic-and that their answers directly relate to the specific situation.

In this contribution, we present selected results from the closed and open questions from the survey, the latter were analysed using an inductively developed coding frame (question 2) and a deductive coding scheme (question 3) that was applied to the answers using the tool QCAMap (2020).

\section{Results}

Out of the $n=29$ participants, seven are professors (24\%), six are (tenured) senior researchers $(21 \%)$, ten are research associates (35\%), three full time lecturers (10\%), and another three indicated their position as "other" (10\%). With 14 participants (48\%) about half of the group is affiliated with the Faculty of Humanities, Social Sciences and Theology; this also being the largest faculty at the university. The other faculties had at least one participant in the sample. The teaching experience in years that participants reported to have, ranges from 0 to 20, as displayed in Table 1.

Table 1: $\quad$ Teaching experience in years $(n=29)$

\begin{tabular}{lcc}
\hline Teaching experience (years) & Absolute & Relative \\
\hline 0 & 1 & $3 \%$ \\
$1-3$ & 5 & $17 \%$ \\
$4-7$ & 4 & $14 \%$ \\
$8-11$ & 7 & $24 \%$ \\
$12-15$ & 2 & $7 \%$ \\
$16-19$ & 4 & $14 \%$ \\
+20 & 6 & $21 \%$ \\
\hline
\end{tabular}

Via the central e-learning support unit, the university offered an ad hoc support program in the beginning and throughout the summer term 2020 as stated above; all of the 29 instructors received some form of support from this program. Following this basic information, we now address the three research questions.

\section{Which digital elements did instructors employ in their teaching?}

Participants were asked to name course formats that they received support by the elearning unit for, the first format that was indicated serves as an example as to which digital elements tools instructors used. The lecture ("Vorlesung") was mentioned 14 times (48\%), followed by nine seminars ("Seminar", 31\%). Two formats were indicated as "other" (7\%), while three participants (10\%) did not state the course format, and one (3\%) skipping this question. 


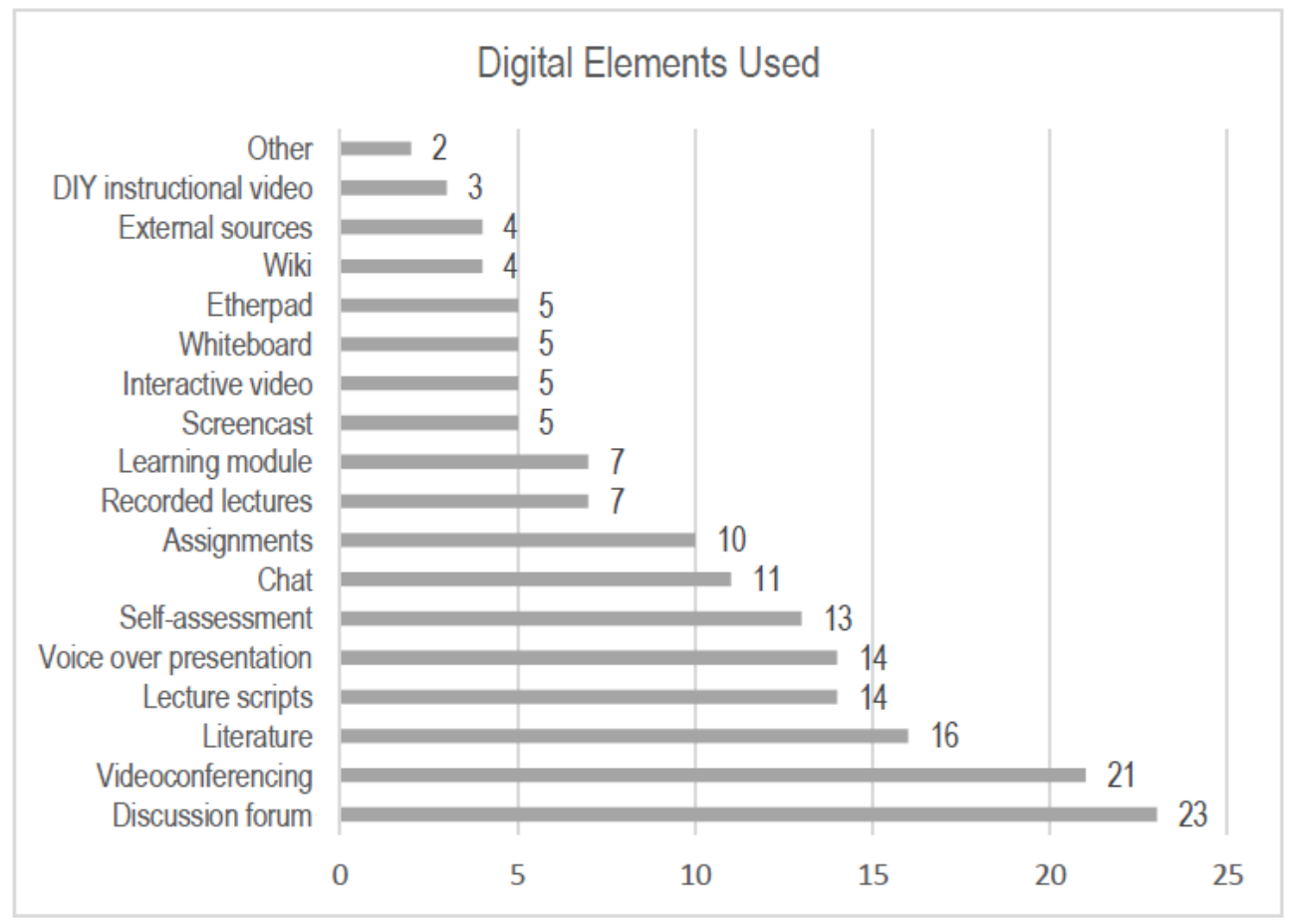

Figure 1. Digital elements used by instructors within one of their course formats, multiple choice $(n=28)$

As depicted in Figure 1, discussion forums and videoconferencing were the two elements employed overwhelmingly often, that is in $75 \%$ and $79 \%$ of the teaching formats. It is also evident that the range of digital elements that are available within the institutional learning management system and/or are being part of support services, e.g. video production, are being employed by instructors.

\section{What do instructors report as their most important learning experience?}

Answers to this question are elicited through inductively coding the participants' responses, choosing phrases that were sometimes drawn directly from participants' quotes or choosing expressions close to their wording. Coding was conducted in German, as the remaining answers will be further coded for the German speaking context within the university. At this point, we also refrained from summarizing answers into larger categories; this will occur at a later stage. 
Bedenlier, S., Schmidt, C., Gerl, S., Hetzner, S., Schliebs, M., \& Sesselmann, K.

"I Can do This - Better than I Thought" - Instructors' Experiences of the Digital Summer Term 2020

Table 2: $\quad$ Inductive categorization of central learning experience, multiple coding

\begin{tabular}{lc}
\hline Category & Absolute Count \\
\hline Little feedback from students & 3 \\
Personal contact cannot be replaced & 4 \\
Possibilities to organize and structure content in classes & 5 \\
High effort is needed & 7 \\
Little personal interaction & 2 \\
Videos are well received by students & 3 \\
Own capabilities & 3 \\
Digital teaching works & 3 \\
Applying digital elements & 5 \\
Reduce content and time & 1 \\
Strenuous & 1 \\
Absolute & 37 \\
\hline
\end{tabular}

Table 2 indicates that instructors realized that preparing for teaching online requires an effort, for example that it takes a long time to prepare videos, that simply "everything takes longer" and that answering to students' email was time consuming as students did not use the forum to ask questions. Topics related to interaction, feedback and the lack of personal, face to face contact were also developed from the material, including statements that it is difficult to transfer lively face to face discussions into the online classroom or that direct student feedback is lacking. However, instructors also commented that they learned about the functionalities of the learning management system (applying digital elements) and that online teaching works as stated in "worked better than expected".

\section{What elements of their online teaching do they want to modify?}

For this question, the participants' quotes underwent deductive categorization according to four main topics. These were provide content/lecture ("vermitteln"), activate ("aktivieren"), scaffold / communicate / organize ("betreuen / kommunizieren / organisieren") and evaluate / assess ("prüfen / testen”). These are the four central components used at the e-learning support unit to guide instructors in designing and implementing digital elements within their courses; grounded in Kerres (2001). As for the opposite of modification to be voiced, a fifth category was included with "Nothing”, in case instructors wanted to continue without changes to their courses.

Table 3: Deductive coding of elements to be modified in further teaching

\begin{tabular}{lc}
\hline Category & Absolute \\
\hline Provide content/lecture & 7 \\
Activate & 9 \\
Scaffold/communicate/organize & 0 \\
Evaluate/assess & 0 \\
Nothing & 3 \\
\hline
\end{tabular}


As depicted in Table 3, participants voiced their intentions to modify parts of their courses in regard to the provision of content or lecturing as well as activation of students. Against the backdrop of having sent out the survey in the middle of the semester, the fact that no one commented on evaluation and assessment is not surprising. Amongst the means that instructors want to employ in order to activate students, using interactive videos is included, as well as making more intensive use of (small) group work during synchronous sessions - and generally commented as "In fully digital offerings, I would integrate more interactive elements, in order to increase the personal touch". As for provision of content and lecturing, participants stated that creating "more/better instructional videos" or using screencasts is on their list.

\section{Discussion}

Instructors in this study were faced with the necessity to switch from face to face teaching to teaching fully online- against the background of not having extensive experience in this area, if at all. About two thirds of them have over eight years of teaching experiences and can therefore be assumed to have established personal teaching patterns for face to face contexts (Baran et al., 2011). The instructors in this sample all sought support of some kind from the institutions ad hoc support program, indicating that they were aware of needing to either change elements of their teaching, develop course structures differently, or gain familiarity with digital tools.

When teaching remotely during the summer term 2020, the range of available digital elements in the learning management system was put to use, with discussion forums (communicate, organize) being used most frequently and the followed by tools related to lecturing and providing content, that is lecture scripts, literature-and videoconferencing. Videoconferencing is an interesting case, as it was perceived to be tiresome for long sessions but in further teaching, using small group activities in synchronous sessions was seen as one way to activate students. The ambivalence of videoconferencing is also noticed in Rapanta et al. (2020).

The central learning experiences that instructors had, occur on different levels, ranging from an improved self-efficacy regarding use of digital elements and online teaching ability to having experienced that effort-also including time resources-is much needed for and within online learning. Relating the perceived little interaction with students and the lack of immediate feedback to the elements that instructors want to change in their further teaching, the wish to "activate" students emerged prominently. Whilst the use of forums as a way to communicate with students was used in the summer term, to further foster communication as a part of interaction seems important (Salmon, n.d.). This might also entail to go back one step from information exchange to online socialization in order to set 
the scene for ongoing interaction more profoundly. In turn, this means for supporting units to pay more attention to guide instructors in this endeavour and consider it in professional development offerings (Adnan, 2018; Baran et al., 2011).

\section{Limitations and Conclusion}

The study presented here is a part of the e-learning support unit's evaluation of how instructors perceived the digital summer term and the services they sought in order to manage the transition from face to face to online teaching. Several limitations to this study exist that stem from the conceptualization of the survey and the number of participants. These need to be noted when evaluating the findings and the reach of the conclusions drawn from them. For example, the group of instructors in this study reported to have zero years of digital teaching experience; however, later questions of the survey indicated that they had, experiences with the use of digital elements within their teaching, such as developing learning modules, using screencasts or video podcasts. Thus, while zero years is reported, this does not equal zero experience as such. Furthermore, the sample size is very small and does not allow for generalizations; it rather provides an exemplary glimpse into how the transition to teaching online worked for this specific group. As the overall analysis of the evaluation is still in progress, we only employed a preliminary category system that still needs to be applied to the remaining participants' answers. This might also result in some categories changing or being modified.

With the pandemic most likely continuing for an indefinite time, instructors and institutions alike face the need to turn the summer 2020 emergency remote teaching into online teaching and learning that is based on established principles of pedagogy and especially drawing on those from the field of distance education (Zawacki-Richter, 2020). What seems to be vital in order to meet this need, is the provision of support structures for instructors so that the emergency remote teacher ultimately becomes an online learning facilitator-who can say about him or herself "I can do this - better than I thought".

\section{References}

Adnan, M. (2018). Professional development in the transition to online teaching: The voice of entrant online instructors. ReCALL, 30(1), 88-111.

https://doi.org/10.1017/S0958344017000106

Baran, E., Correia, A.-P., \& Thompson, A. (2011). Transforming online teaching practice: Critical analysis of the literature on the roles and competencies of online teachers. Distance Education, 32(3), 421-439. https://doi.org/10.1080/01587919.2011.610293 
Barton, D. C. (2020). Impacts of the COVID-19 pandemic on field instruction and remote teaching alternatives: Results from a survey of instructors. Ecology and Evolution, ece3.6628. https://doi.org/10.1002/ece3.6628

Bates, A.W. (2020, March 9). Advice to those about to teach online because of the coronavirus. Tony Bates [Blog post]. Retrieved September 14, 2020, from https://www.tonybates.ca/2020/03/09/advice-to-those-about-to-teach-online-becauseof-the-corona-virus/

Bates, A. W. (2019). Teaching in a digital age - Second edition. Vancouver, B.C.: Tony Bates Associates Ltd. Retrieved from https://pressbooks.bccampus.ca/teachinginadigitalagev2/

Brooks, D. C., \& Grajek, S. (2020, March 12). Faculty readiness to begin fully remote teaching. EDUCAUSEreview. https://er.educause.edu/blogs/2020/3/facultyreadiness-to-begin-fully-remote-teaching

Bundesministerium für Bildung und Forschung. (2020). Retrieved September 9, 2020, from https://www.qualitaetspakt-lehre.

European Distance and E-Learning Network. (2020). EDEN webinar series: Education in time of a pandemic \#onlinetogether \#covid19. Retrieved from https://www.edenonline.org/covid-webinar-series/

Hochschulforum Digitalisierung. (2020). Hochschulen und Corona: Was jetzt? Retrieved from https://hochschulforumdigitalisierung.de/de/hochschulen-und-corona-was-jetzt

Hodges, C., Moore, S., Lockee, B., Trust, T., \& Bond, A. (2020). The difference between emergency remote teaching and online learning. EDUCAUSEreview.

Kerres, M. (2001). Multimediale und telemediale Lernumgebungen: Konzeption und Entwicklung ( $2^{\text {nd }}$ ed.). Oldenbourg: De Gruyter.

Marinoni, G., van't Land, H., \& Jensen, T. (2020). The impact of Covid-19 on higher education around the world. IAU Global Survey Report. Retrieved from https://bit.ly/2U3jd6F

O’Keefe, L., Rafferty, J., Gunder, A., Vignare, K. (2020, May 18). Delivering high-quality instruction online in response to COVID-19: Faculty playbook. Every Learner Everywhere. http://www.everylearnereverywhere.org/resources

QCAmap (2020). Retrieved from https://www.qcamap.org/ui/login

Rapanta, C., Botturi, L., Goodyear, P., Guàrdia, L., \& Koole, M. (2020). Online university teaching during and after the Covid-19 crisis: Refocusing teacher presence and learning activity. Postdigital Science and Education. https://doi.org/10.1007/s42438-020-00155$\mathrm{y}$ 
Salmon, G. (n.d.). The five stage model. Retrieved September 15, 2020 from

https://www.gillysalmon.com/five-stagemodel.html

Zawacki-Richter, O. (2020). Halb zog sie ihn, halb sank er hin... Covid-19 als Chance für die Digitalisierung von Studium und Lehre? Das Hochschulwesen, 68(4+5).

\section{Acknowledgement}

Special thanks go to our student assistant for the operative help during the evaluation. 